\title{
História, ausência e mito historiográfico: um estudo sobre o diálogo entre Marshall Sahlins e a História (1950-1980)
}

\author{
History, absence and historiographical myth: a study about the \\ dialogue between Marshall Sahlins and History (1950-1980) \\ Felipe Souza Leāo de Oliveira
}

\section{RESUMO}

O antropólogo norte-americano Marshall Sahlins é famoso por seu diálogo com a História. Paradoxalmente, entre 1950 e 1980, esse diálogo foi marcado pela ausência de historiadores. Mas como isso foi possível? Como Sahlins manteve um diálogo com a História durante tanto tempo com historiadores ausentes? Nossa hipótese é que isso se tornou factível graças a um mito historiográfico presente nos seus textos: o mito do historiador convencional. Para testarmos nossa hipótese, trabalharemos com escritos de Sahlins e outros antropólogos. Tentaremos, com esses escritos, mapear seu diálogo com a História e reconstituir o contexto em que ele se desenvolveu. Usaremos também o conceito de mito historiográfico, do historiador Sérgio da Mata. Nossa conclusão é que esse mito historiográfico de Sahlins foi sustentado pela ausência de historiadores, e vice-versa - algo que deixou sua marca no diálogo entre ele e a História.

\section{PALAVRAS-CHAVE}

Marshall Sahlins, Antropologia, Historiografia.

\section{ABSTRACT}

The North-American anthropologist Marshall Sahlins is famous for his dialogue with History. Paradoxically, between the decades of 1950 and 1980, this dialogue was marked by the absence of historians. But how was this possible? How could Sahlins have maintained this dialogue with History for so long with absent historians? Our hypothesis is that this became feasible thanks to a historiographical myth that was present in his texts: the myth of the "conventional historian". In order to test this hypothesis, we will work with writings by Sahlins and other anthropologists. We will try, with these writings, to chart his dialogue with History and reconstitute its context of development. We will also use the concept of "historiographical myth" by historian Sérgio da Mata. Our conclusion is that Sahlins historiographical myth was sustained by the absence of historians and viceversa - something that left its mark in the dialogue between him and History.

\section{KEYWORDS}

Marshall Sahlins, Anthropology, Historiography. 
Muito já se escreveu sobre a relação entre o antropólogo norte-americano Marshall Sahlins e a História. Para a antropóloga Lilia Moritz Schwarcz, ele "merece um lugar especial" nessa relação (SCHWARCZ 2000, p. 128), na medida em que tornou possível uma "abordagem cultural" atenta para "a noção de dinâmica cultural e da circulação de ideias" (SCHWARCZ 2006, p. 31). O antropólogo Adam Kuper viu na obra de Sahlins uma ideia de História pensada culturalmente, algo especialmente útil para a Antropologia, uma disciplina em que a cultura é um importante conceito (KUPER 1999, p. 159 e seguintes). A antropóloga Aletta Biersack, em outra ocasião, destacou a contribuição de Sahlins para outros dois conceitos: evento e estrutura (BIERSACK 1989, p. 84 e seguintes).

Entre os historiadores, Peter Burke enfatizou a importância de Sahlins para a reflexão sobre os conceitos de sistema e evento (BURKE 2005, p. 165 e 169-170). No âmbito da História da Historiografia, Michael Goldsmith destacou a contribuição de sua obra para a historiografia das ilhas do Pacífico, em especial Fiji e Havaí (GOLDSMITH 2006). O historiador François Hartog criou um importante conceito a partir da leitura do antropólogo norte-americano: regime de historicidade (HARTOG 2013).

Com exceção de Kuper e Goldsmith, todos esses autores tendem a enfatizar os textos publicados por Sahlins na década de 1980, quando ele tentou aproximar a Antropologia da História, atraindo pesquisadores de ambas as áreas. Contudo, devemos ter em mente que seu diálogo com a História é muito anterior a isso, remetendo à década de 1950. Além disso, entre as décadas de 1950 e 80, uma das principais características desse diálogo foi a ausência de historiadores. A história dessa ausência, entretanto, permanece ignorada até hoje.

Diante disso, esse artigo tem dois objetivos: (1) reconstruir brevemente essa história e (2) propor uma resposta ao seguinte problema: como Sahlins foi capaz de dialogar com a História durante tanto tempo, sem mencionar qualquer historiador específico? Nossa hipótese é que isso foi possível graças à presença de um mito historiográfico em seu texto: o historiador 
convencional. Portanto, do ponto de vista cronológico, esse artigo vai abranger o período que vai da década de 1950 até a década de 1980. Escolhemos iniciar nessa década, pelo fato de ela representar o início da trajetória intelectual de Sahlins, além de significar o começo de seu diálogo com a História, e finalizamos com a década de 1980, na medida em que vemos nela o fim dessa ausência de historiadores e desse mito historiográfico em sua obra.

Ao todo, este artigo será dividido em cinco partes. Na primeira parte, desenvolveremos uma breve história da relação entre História e Antropologia, no período que se estende do século XIX até o início da trajetória intelectual de Sahlins na década de 1950. Para isso, escolhemos como ponto de partida a biografia e obra do antropólogo alemão Franz Boas. Essa escolha se justifica por duas razões: primeiro, porque Boas teve um papel central na história do diálogo entre antropólogos e historiadores nos Estados Unidos; segundo porque Sahlins construirá suas reflexões, em parte, a partir de sua oposição a Boas e sua definição de História. Na segunda parte, voltaremos a atenção para um antropólogo que exerceu grande influência sobre Sahlins: o norte-americano Leslie Alvin White. Mostraremos que historiadores estiveram ausentes dos escritos de White apesar de ele ter dialogado com a História. Argumentaremos também que White recorreu a um mito historiográfico para conduzir esse diálogo: o historiador convencional. Na terceira parte, analisaremos as críticas feitas pelo antropólogo Alfred Louis Kroeber a essa ausência de historiadores nos textos de White. Na quarta parte, mostraremos que as críticas de Kroeber foram ignoradas por Sahlins, enquanto esse último adotará o mito historiográfico do historiador convencional a partir de White. Isso, segundo nosso argumento, permitirá que Sahlins dialogue com a História sem citar um único historiador durante muitos anos. Por fim, na quinta e última parte, apresentamos uma síntese de nosso problema e hipótese central, acrescentando algumas ponderações. 


\section{Prelúdio à ausência}

Quem lê sobre a história da Antropologia nos Estados Unidos descobre que o antropólogo alemão Franz Boas teve um papel fundamental nela, ajudando a definir o caráter nacional da pesquisa antropológica neste país (STOCKING, JR. 1974, p. 1).

Nascido em 1858, Franz Uri Boas saiu da Alemanha e mudou-se para os Estados Unidos em 1887, quando foi contratado para o cargo de diretor assistente na revista Science, um periódico da American Association for the Advancement of Science (PATTERSON 2001, p. 45). Boas, nesse mesmo ano, envolveu-se também em uma polêmica com a perspectiva evolucionista de Otis T. Mason, o curador de Etnologia do United States National Museum. Os museus, nessa época, eram mais importantes para a Antropologia do que são hoje, já que os critérios adotados por um curador, ao organizar uma exposição, podiam trazer sérias consequências para a disciplina como um todo (STOCKING, JR. 1974, p. 57-58).

Mason era um adepto do Evolucionismo, uma das perspectivas teóricas mais influentes na Antropologia durante a segunda metade do século XIX. O termo evolucionismo é derivado de evolução, palavra normalmente associada à Biologia e ao biólogo inglês Charles Darwin. No século XIX, tanto Darwin (1809-1882) quanto o seu colega Alfred Russell Wallace (1823-1913) abriram novas possibilidades de estudo na Biologia, ligando a palavra evolução ao termo seleção sexual. Segundo a teoria construída por eles, mutações acidentais em organismos podem dar origem a novas formas de vida com o passar do tempo. Contudo, somente aqueles organismos que melhor se adaptem ao meio em que vivem são capazes de transmitir traços e características genéticas para gerações futuras (BARNARD 2000, p. 29).

O sucesso da teoria evolucionista terminou por inspirar a Antropologia na segunda metade do século XIX. A partir daí, muitos dos principais antropólogos desse período, como Edward Burnett Tylor, Lewis Henry Morgan, John Lubbock e Sir Henry 
Maine ficaram conhecidos como evolucionistas (STOCKING, JR. 1974, p. 58; BARNARD 2000, p. 27 e seguintes). Antropólogos evolucionistas, em geral, tendiam a interpretar o curso total do desenvolvimento humano como um processo evolutivo que começa no passado e continua no presente. Segundo a lógica desse processo, sociedades primitivas como tribos e grupos nômades evoluem e se tornam mais complexas até alcançarem formas de organização social típicas da Europa Ocidental (STOCKING, JR. 1982, p. 119). Com base nesse princípio, elementos culturais como artes, crenças e costumes são classificados e comparados de acordo com uma linha evolutiva comum a toda a humanidade. Isso, por sua vez, permite que esses mesmos elementos sejam distribuídos em uma sequência temporal, de acordo com a provável ordem de sua evolução (STOCKING, JR. 1982, p. 80).

Agora, sabendo do que foi dito até aqui, podemos retornar à polêmica entre Boas e Mason. Esse último, em certa ocasião, separou objetos do museu em grupos como máscaras, panelas, ferramentas para trabalhar madeira, etc. Em seguida, distribuiuos ao longo de uma sequência evolutiva, de acordo com seu nível de complexidade, partindo de objetos simples e antigos para aqueles mais recentes e complexos. Boas, entretanto, discordou desses critérios. Para o antropólogo alemão, eles não explicavam o desenvolvimento histórico desses objetos, limitando-se a distribuí-los em uma sequência preestabelecida e deixando de relacioná-los entre si (PATTERSON 2001, p. 47; STOCKING, JR, 1974, p. 61-62). Essas críticas, entretanto, foram escritas em uma época em que o Evolucionismo já era bastante questionado. Essa perspectiva havia atingido o auge na década de 1860. Entretanto, no fim do século XIX, ela começa a declinar. Não por acaso, até mesmo um de seus maiores defensores, o antropólogo inglês Edward Tylor, recebeu as críticas de Boas com entusiasmo, vendo nelas uma importante e necessária chance de reforma (STOCKING, JR. 1982 , p. $74,100,114-115$ e 211 ).

No início do século $X X$, porém, Boas abandonou sua 
preocupação com o Evolucionismo e voltou-se para outros interesses. Um deles foi a História, uma ciência que, segundo ele, teria algo em comum com a Física: a busca pelo estabelecimento de fatos e verdades eternas. Cada uma, entretanto, seguiria um caminho próprio. O físico compara fatos entre si, tentando compreender o fenômeno a que eles se referem. Fatos individuais, nesse sentido, são menos importantes que as leis deduzidas a partir deles. O historiador, em contrapartida, enfatiza a compreensão de fatos individuais e vê a busca por leis como algo menos importante. Assim, tanto as ciências humanas como a História, quanto as ciências naturais como Física, são igualmente científicas. A diferença entre elas é que cada uma constitui um modo diferente de olhar para o mundo (STOCKING, JR. 1974, p. 9 e 11-12).

Quando analisamos a formação intelectual de Boas, descobrimos que ele se aproximou de, pelo menos, duas definições de História: uma associada ao historiador alemão Leopold von Ranke, voltada para o estudo detalhado e concreto de fatos individuais do passado; e outra ligada ao filósofo alemão Wilhelm Dilthey, que separava as ciências naturais das ciências históricas, repensando pressupostos metafísicos da investigação histórica. No início de sua carreira, Boas havia definido a abordagem dos físicos como diferente daquela dos historiadores. Com o passar do tempo, ele buscou integrá-las, algo que terminou por gerar graves problemas. Por exemplo: quando se afastou de Dilthey, Boas adotou uma definição de história tradicional e ortodoxa, semelhante àquela de Ranke. O problema é que essa definição assumiu certos procedimentos e abordagens (como a crítica de documentos escritos) que dificilmente seriam postas em prática por antropólogos, já que sociedades estudadas por eles, em geral, são desprovidas de qualquer registro documental. Por causa disso, Boas não foi capaz de pôr sua abordagem histórica em prática algo que ele mesmo veio a reconhecer depois (STOCKING, JR. 1974 p. $11-13$ e 18$)$.

Com o passar do tempo, a aproximação entre Antropologia e História defendida por Boas é bastante contestada por 
importantes antropólogos. Para o inglês Alfred Reginald Radcliffe-Brown, por exemplo, antropólogos que definem o próprio trabalho como um tipo de estudo histórico cometem um erro grave: terminam por produzir trabalhos puramente especulativos ou meramente conjecturais. O problema de explicações históricas, segundo ele, não é o fato de serem ruins, mas sim de serem desnecessárias (RADCLIFFE-BROWN 1965, p. 2-3).

Outro exemplo é aquele do antropólogo norte-americano George Peter Murdock. Indo além de Radcliffe-Brown, Murdock adotou uma abordagem estatística, comparativa e generalizante, opondo-se, assim, à perspectiva histórica e particularista de Boas (HARRIS 2001, p. 606-607). Esse último, segundo Murdock, foi "extravagantemente superestimado por seus alunos"1 (apud HARRIS 2001, p. 607), que "se perderam em um labirinto de detalhes inconsequentes", ${ }^{2}$ perdendo de vista a "função primária de uma ciência, [que é] a formulação e teste de generalizações" ${ }^{\prime 3}$ (apud WHITE 2005, p. v).

Entre os críticos de Boas, porém, nenhum foi tão longe quanto o norte-americano Leslie Alvin White, um dos professores mais influentes na trajetória intelectual de Sahlins, como veremos a seguir.

\section{A ausência adotada}

Entre os anos de 1927 e 1930, Leslie White trabalhou como professor de Antropologia na Universidade de Buffalo. Durante esse tempo, se interessou pelo estudo dos índios Seneca Iroquois, moradores de uma reserva próxima à universidade. Por causa desse interesse, decidiu ler um livro clássico da Antropologia a respeito desse povo, o The League of Iroquois, A Liga dos Iroquois, uma obra publicada em 1851, de autoria do antropólogo norte-americano Lewis Henry Morgan. White se empolgou tanto com essa obra que decidiu ler outro livro de Morgan, o clássico Ancient Society, Sociedade Antiga, de 1877. Depois disso, editou vários volumes de cartas e artigos de Morgan, além de escrever a introdução de uma edição do Ancient Society (WHITE 2005, p. viii-ix; SERVICE 1976).
1. No original: "extravagantly overrated by his students".

2. No original: "have lost themselves in a maze of inconsequential facts".

3. No original: "the primary function of a science, the formulation and testing of generalizations". 
Um dos aspectos mais interessantes para White, na obra de Morgan, foi a perspectiva teórica contida nela: o Evolucionismo. Enquanto se interessava por essa perspectiva, ele se distanciava de um de seus maiores críticos: Franz Boas. No ano de 1960, por exemplo, White reclamava que "a filosofia antievolucionista do grupo de Boas ainda está sendo ensinada em vários departamentos de Antropologia nos Estados Unidos" ${ }^{\prime 4}$ (SAHLINS; SERVICE 1988, p. v). Apesar disso, essa filosofia antievolucionista estaria mostrando cada vez mais sinais de esgotamento, de modo que "mais uma vez a teoria da evolução está em marcha"5 (SAHLINS; SERVICE 1988, p. vii). As suas críticas, porém, não pararam aqui. Indo além delas, ele decidiu se afastar de uma das ciências preferidas do antropólogo alemão: a História. Uma das referências mais antigas à História, na obra de White, pode ser encontrada em um artigo de sua autoria, intitulado Science is Sciencing, Ciência é Fazer Ciência, publicado em 1938. É possível vermos nesse artigo tanto a sua definição de História quanto o contexto em que ela foi pensada: sua filosofia da ciência.

White defende neste artigo que a ciência é uma forma de lidar com a experiência ou realidade, tornando-a compreensível. A ciência lida com o particular através do universal; a arte lida com o universal mediante o particular. Para ilustrar essa distinção, recorre a um personagem da literatura norteamericana: o escravo negro Uncle Tom, do livro Uncle Tom's Cabin (A Cabana do Pai Tomás), de Harriet Beecher Stowe. Um cientista, segundo ele, estuda Uncle Tom, um particular, como apenas um elemento de algo mais interessante: a grande massa de escravos negros, um universal. Um artista, ao invés disso, faz o leitor confrontar o problema da escravidão, um universal, através da vida de Uncle Tom, um particular (WHITE 1938, p. 369).

Ao todo, para White, existem três formas de praticar Ciência: (1) por meio da análise do aspecto temporal da realidade, como faz a História; (2) através do estudo de seu aspecto espacial, como vemos na investigação da estrutura do

\section{No original: "the antievolutionist phi- losophy of the Boas group is still being taught in many de- partments of Anthro- pology in the United States". \\ 5. No original: "once more the theory of evolution is on the march".}


átomo; ou (3) mediante o exame do produto da relação entre tempo e espaço. Um exemplo de produto dessa relação são as espécies animais no nosso planeta. Toda espécie, segundo White, é um produto da interação entre um processo temporal (como uma série de acontecimentos) e um determinado espaço (como o ambiente em que a espécie vive). Assim, um exemplo de estudo que ilustra a terceira forma de praticar Ciência é o evolutivo, que descreve e interpreta as formas assumidas por uma espécie, enquanto um produto da interação entre tempo e espaço (WHITE 1938, p. 374 e seguintes).

Dentre essas três práticas, a mais interessante para os nossos propósitos é a História. Essa ciência, segundo White, lida principalmente com o aspecto temporal da realidade. Isso não significa que historiadores ignorem o aspecto espacial: significa apenas que eles dão um maior destaque ao tempo (WHITE 1938, p. 374). A História, segundo esse argumento, é formada por eventos únicos, mas tudo que existe no tempo pode, em princípio, se tornar objeto de análise histórica: estrelas, sistemas solares, rios, plantas, animais, indivíduos, instituições e costumes sociais. A partir daí, ciências como Astronomia, Física, Geologia e Antropologia são históricas pelo menos em parte (WHITE 1938, p. 374-375).

Diante disso, podemos lançar a seguinte questão: quais são os historiadores que trabalham com essa definição de História proposta por White? Quando ele escreve sobre os tipos de ciência e as diferentes formas de praticá-las, o nome de um astrônomo é citado: o norte-americano Harlow Shapley (WHITE 1938, p. 370). Ao discutir o conceito de Ciência Social, sua referência é o antropólogo norte-americano Earnest Albert Hooton (WHITE 1938, p. 371). Uma reflexão sobre diferentes formas de evolução é acompanhada da citação de seis cientistas (WHITE 1938, p. 385). Além disso, quando menciona escolas e especializações dentro da Sociologia e Antropologia - como morfologia social, escola formalista de antropologia cultural e escola de Chicago - seu texto é recheado de referências a oito pesquisadores dessas áreas (WHITE 1938, p. 386). Enquanto 
isso, nenhum historiador é citado.

Essa ausência de historiadores continua até quando White cita categorias e questões que interessam a eles. Por exemplo: quando reflete sobre a categoria tempo, ele não cita o trabalho de um historiador, mas um texto do físico Albert Einstein (WHITE 1938, p. 374). Quando escreve sobre a ideia de evento, recorre a um físico (Einstein) e a um matemático (Hermann Minkowski) (WHITE 1938, p. 373). Quando menciona áreas de estudo possíveis dentro da História - história das nações, tribos, instituições, ferramentas, ideias e crenças - nem um historiador é citado (WHITE 1938, p. 386).

Essa ausência se repete sete anos depois, em outro artigo de sua autoria, intitulado History, Evolutionism, and Functionalism: Three Types of Interpretation of Culture, História Evolucionismo, e Funcionalismo: Três Tipos de Interpretação da Cultura, publicado em 1945. Agora, além das três formas de prática científica, White defende a existência de três modos equivalentes de interpretação cultural: a interpretação histórica, a evolucionista e a funcionalista.

Para compreender esses três modos, imaginemos um pesquisador ou pesquisadora que decida analisar a linguagem escrita de um povo. Optar por uma interpretação funcionalista significa analisar a estrutura dessa linguagem ou a função de suas partes - como letras e sílabas na formação de palavras. A interpretação evolucionista, por sua vez, enfatiza os princípios gerais do surgimento e os padrões de transformação da linguagem humana em geral, fazendo da menção a qualquer linguagem específica algo que serve somente para fins ilustrativos. Por último, se escolher a perspectiva histórica, o pesquisador ou pesquisadora deverá se voltar para o surgimento e transformações da linguagem que ele ou ela quer estudar. Um exemplo de estudo histórico é a análise da difusão de uma linguagem através de povos e lugares distintos ao longo do tempo (WHITE 1945, p. 240 e seguintes).

A História, em meio a essa discussão, continua a ser o 
estudo da "sequência cronológica de eventos únicos"6 (WHITE 1945 , p. 222). Aqui, mais uma vez, historiadores continuam ausentes; só que o mesmo não pode ser dito da grande quantidade de cientistas sociais (WHITE 1945, p. 221 e 223 e seguintes), filósofos (WHITE 1945, p. 245) e físicos (WHITE 1945 , p. 234,237 e 246-247) citados no texto.

A despeito disso, existe algo digno de nota no texto de White: as diversas expressões usadas por ele no lugar de nomes específicos de historiadores. Um exemplo disso é a expressão historiador convencional (WHITE 1938, p. 376) ou "aqueles que carregam o rótulo de 'historiador""7 (WHITE 1938, p. 374). Essas expressões permitem que White escreva sobre 0 propósito e objetivo do historiador (WHITE 1945, p. 242) sem citar ninguém em particular, fazendo da figura do historiador um mito historiográfico em seu texto (para mais exemplos ver: WHITE 1945 p. 232, 234, 235, 236, 238, 239, 244; WHITE 2005 p. $8,10,94,191,268,277,280$; WHITE 2007 , p. 30).

O historiador Sérgio da Mata define um mito historiográfico como "uma crença, ou articulação de várias crenças, coletivamente construída(s) e a partir de então associada(s) à obra e à trajetória de um historiador ou grupo de historiadores". Essa crença ou conjunto de crenças permanece sempre "incólume ante toda e qualquer contraposição com os 'fatos'". Sua força, nesse sentido, "não advém do real, mas do desejo de tornar algo real", enquanto "o olhar questionador e o rigor acadêmico cedem à tradição e ao argumento de autoridade". $\mathrm{Na}$ prática, mitos historiográficos "prescindem (e, por sua própria natureza, têm de prescindir) de qualquer formulação sistemática e crítica para se perpetuarem". Um exemplo disso é a expressão historiografia positivista, um mito historiográfico que foi muito útil na legitimação da perspectiva teórica conhecida como "escola do Annales" (MATA 2015, p. 188).

Essa definição de mito historiográfico pode ser muito proveitosa para entendermos os significados que Leslie White atribui à figura do historiador em seus textos. Neles, como vimos, nenhum historiador específico é citado. No lugar disso,
6. No original: "chronological sequence of unique events".

7. No original: "those who bear the label 'historian'". 
aparecem mitos historiográficos como aqueles que carregam o rótulo de historiador ou o historiador convencional. Essas expressões se transformam em mitos historiográficos na medida em que nenhum exemplo específico é capaz de desfazêlos. Caso um ou mais exemplos sejam citados, White pode simplesmente ignorá-los ou tratá-los como meras exceções de uma tendência mais ampla: aquela do historiador típico ou convencional. Mais tarde, o "olhar questionador e o rigor acadêmico" de Sahlins cederão "à tradição e ao argumento de autoridade" de Leslie White. Antes disso, porém, um colega de White verá um erro nessa ausência de historiadores: Alfred Louis Kroeber.

\section{A ausência criticada}

Um ano depois do artigo History, Evolutionism, and Functionalism: Three Types of Interpretation of Culture, de 1945, diversos aspectos das reflexões de Leslie White são criticadas. Entre eles dois se destacam: a ausência de historiadores e sua definição de História. O crítico, nesse caso, será o antropólogo norte-americano Alfred Louis Kroeber, um colega de White e professor de Antropologia na Universidade da Califórnia. Antes de publicar o artigo Science is Sciencing, em 1938, White havia encaminhado um esboço do texto para Kroeber (PEACE 2004, p. 103). Depois disso, eles trocam várias cartas. Nelas, é possível vermos uma relação cordial e amistosa entre os dois. Contudo, podemos ver também uma certa frustração em ambos, já que um parece sempre disposto a discordar dos princípios mais básicos e fundamentais do outro (PEACE 2004, p. 131).

Em 1946, Kroeber decide publicar o artigo History and Evolution, História e Evolução, como uma resposta ao texto de White publicado no ano anterior. White, segundo Kroeber, havia definido o "tratamento histórico como estando preocupado somente com eventos únicos em sua sequência cronológica"8. Essa definição, entretanto, é limitada demais, já que reduz o trabalho do historiador a uma mera lista de nomes, datas e
8. No original: "historical treatment as being merely concerned with unique events in their chronological sequence". 
lugares; ou a um mero mapeamento de "perambulações de itens desprendidos e desvinculados [entre si] ao longo do tempo e do espaço"'. Historiadores, segundo Kroeber, não descrevem eventos de forma desinteressada. Muitos deles, ao invés disso, analisam estruturas e funções de aspectos das mais diversas culturas e sociedades - como no caso daquela interpretação funcionalista, descrita por White. Outros interpretam os produtos da relação entre tempo e espaço, enquanto lidam com vastos períodos de tempo - de forma semelhante àquela abordagem evolucionista (KROEBER 1946, p. 1-3). Ainda de acordo com Kroeber, White erra quando diz que o tempo é o elemento mais importante nos trabalhos de História. Muitos historiadores, ao invés disso, analisam momentos históricos específicos, sem se preocuparem com o problema da mudança temporal. Quando agem assim, buscam compreender as relações sociais e culturais entre um momento de mudança e outro, o que Kroeber chama de "tratamento histórico sincrônico"10 (KROEBER 1946, p. 1213). Mas onde estão as evidências que apoiam o argumento de Kroeber? No seu texto, ele cita várias: o livro La Cité antique, A Cidade antiga, de Fustel de Coulanges; Les villes du Moyen Age, As vilas da Idade Média, de Henri Pirenne; The Frontier in American History, A Fronteira na História Americana, de Frederick Jackson Turner; o historiador suíço Jacob Burckhardt, o romano Tácito e seis outros (KROEBER 1946, p. 13).

Depois disso, prosseguindo em seu argumento, Kroeber acrescenta que White adota um conceito limitado de História porque quer, na verdade, enriquecer seu termo preferido: evolução (KROEBER 1946, p. 2). No texto de 1945, White havia citado o livro The Evolution of Physics, A Evolução da Física, dos físicos Albert Einstein e Leopold Infeld. Tal obra, segundo ele, é um exemplo de trabalho evolucionista. A partir desse exemplo, ele busca separar as palavras história e evolução. Einstein e Infeld, segundo sua lógica, não constroem uma narrativa de eventos únicos e particulares. O que eles tentam, ao invés disso, é "mostrar como a filosofia da Física cresceu e se desenvolveu, como uma forma de teoria física cresceu para se tornar outra"11. Por causa disso, o "livro poderia ter sido escrito
9. No original: "wanderings of detached and unrelated items through time and space".

10. No original: "synchronic historical treatment".

11. No original: "to show how the philosophy of physics has grown and developed, how one form of physical theory has grown into another". 
sem nenhuma menção específica a um único homem, uma única data ou lugar". ${ }^{12}$ Isso faz dele um trabalho evolucionista, não de História (WHITE 1945, p. 237-238).

Kroeber, por sua vez, discorda desse argumento. Ele acredita que White reduz a obra supostamente evolucionista de Einstein e Infeld a uma "interpretação abreviada, mas genuinamente histórica de [certas] tendências"13 - só que "com a maior parte de fatos comprobatórios e específicos omitidos". ${ }^{14}$ Além disso, se esse livro é um exemplo de obra evolucionista, Kroeber, então, pergunta: "será que o evolucionismo de White se resume a uma história abreviada?" (KROEBER 1946, p. 14). ${ }^{15}$ Kroeber considera que sim. White havia citado diversos exemplos de processos evolutivos, como a formação e desenvolvimento do universo, a constituição da vida orgânica e o desenvolvimento de culturas humanas. O problema, segundo Kroeber, é que esses processos não passam de "histórias meramente grandes" (KROEBER 1946, p. 13-14). ${ }^{16}$

\section{A ausência retomada}

Cinco anos após a publicação do artigo de Kroeber, em 1951, Marshall Sahlins concluiu sua graduação em Antropologia na Universidade de Michigan. Depois disso, termina o mestrado nessa mesma área e instituição em 1952. Seu doutorado, também em Antropologia, é concluído em um lugar diferente: a Universidade de Columbia. O ano de conclusão é 1954, com a defesa da tese Social Stratification in Polynesia (Estratificação Social na Polinésia). Quatro anos depois, em 1958, essa tese é publicada em forma de livro (GOLUB; KELLY; ROSENBLATT 2016 , p. 6 e seguintes; SAHLINS 2005b, p. 11). Na seção de agradecimentos, Sahlins agradece a Leslie White por sua orientação e estímulo (SAHLINS 1958, p. v).

Sua tese de doutorado consiste no estudo da relação entre as diferenças em um aspecto dos sistemas sociais da Polinésia - a estratificação social - e as diferenças na adaptação de culturas ao seu ambiente. Seu objetivo, a partir daí, é "explicar a diferenciação social dentro de um grupo de culturas geneticamente
12. No original: "book could have been written without specific mention of a single man, a single date or place".

13. No original: "genuinely historical but summarized interpretation of trends".

14. No original: "with most of the specific evidential facts omitted".

15. No original: "could it be that White's evolutionism boils down to summarized history?".

16. No original: "merely large histories". 
relacionadas" ${ }^{\prime 17}$ : as culturas polinésias (SAHLINS 1958, p. ix).

No texto de sua tese, é possível vermos certos contornos da definição de História adotada por ele. Ela aparece de forma implícita no capítulo 7, cujo título é "Stratification and History", Estratificação e História. Nesse capítulo, Sahlins investiga a possibilidade de uma estratificação social ser maior em uma corrente da cultura polinésia (a Ocidental) do que em outra (a Central-marginal ou Oriental). Essas duas correntes, segundo ele, são produtos da difusão de elementos culturais, decorrentes de dois centros difusores de influência cultural: as ilhas Fiji, no ocidente, e as ilhas Society, no oriente. Para analisar o grau de estratificação social presente nelas, ele volta sua atenção para aqueles elementos culturais que persistem como sobrevivências ou formas vestigiais a partir desses centros difusores. Um exemplo dessas sobrevivências são os rituais de santificação de chefes tribais que continuam a existir, mesmo depois de terem perdido sua relevância política e econômica (SAHLINS 1958 , p. 136-138).

A História, portanto, aparece na tese de Sahlins sob a forma de sobrevivências ou formas vestigiais daqueles elementos culturais que se difundiram geograficamente ao longo do tempo. A ideia de sobrevivência é uma herança do século XIX. O inglês Edward Burnett Tylor, por exemplo, já escrevia sobre isso (STOCKING, JR. 1982, p. 97). O conceito de difusão, por sua vez, tem uma longa trajetória na história da Antropologia (BARNARD 2000, p. 47 e seguintes). O próprio Leslie White, nos artigos de 1938 e 1945, associou à História a ideia de difusão várias vezes. No artigo de 1938, por exemplo, escreve que as ciências voltadas para o aspecto temporal da realidade, como a História, tendem a enfatizar o problema da difusão racial, quando estudam seres humanos (WHITE 1938, p. 385). Depois disso, no texto de 1945, afirma que historiadores querem conhecer tanto o lugar em que um objeto surgiu quanto aqueles lugares para onde ele se difundiu posteriormente (WHITE 1945, p. 236).

Assim, quando utiliza palavras como sobrevivência e 
difusão, Sahlins pensa a História de um modo tipicamente evolucionista, influenciado por Leslie White. Isso irá se tornar mais explícito dois anos depois, na coletânea intitulada Evolution and Culture (Evolução e Cultura), organizada por Sahlins e um colega seu de Michigan, o antropólogo norteamericano Elman Service - alguém que foi também aluno de Leslie White. Em 1958, Sahlins e Service se reúnem para escrever um artigo juntos. Com o passar do tempo, o artigo cresce em tamanho e complexidade. Por esse motivo, eles organizam um simpósio para discuti-lo, intitulado "Principles of Culture Evolution", Princípios de Evolução Cultural, realizado no encontro anual da American Anthropological Association, na cidade de Madison, Wisconsin, entre os dias 14 e 16 de maio de 1959. Além de Sahlins e Service, participam também do simpósio os antropólogos Thomas Harding e David Kaplan. O resultado desse evento é a coletânea Evolution and Culture, formada por artigos de Sahlins, Service, Harding e Kaplan (SAHLINS; SERVICE 1988, p. 123-124). No artigo escrito para tal coletânea, intitulado "Evolution: Specific and General", Evolução: Específica e Geral, Sahlins tenta desfazer certas imprecisões conceituais supostamente presentes nas reflexões de antropólogos evolucionistas (SAHLINS; SERVICE 1988, p. 12). Ele propõe, para isso, dois novos conceitos: evolução específica e evolução geral.

Evolução específica denomina o processo evolutivo no qual novas formas se diferenciam de formas anteriores, enquanto tentam se adaptar ao meio em que vivem. Evolução geral, por sua vez, refere-se ao processo de geração de progresso, ou seja, a produção de "formas mais elevadas [que] emergem, e ultrapassam, as [formas] inferiores" (SAHLINS; SERVICE 1988 , p. 12-13). ${ }^{18}$ Sahlins, inicialmente, propõe esses dois conceitos em meio a uma discussão sobre a evolução biológica. Logo em seguida, porém, decide usá-los para compreender a evolução cultural. A cultura, segundo seu argumento, "continua o processo evolucionário [biológico] por novos meios", 19 o que permite que palavras originalmente usadas no contexto da evolução biológica - adaptação e forma, por exemplo - possam 
ser transferidas para o entendimento da evolução cultural. Assim, por exemplo, "a cultura se diversifica através da especialização adaptativa e ela ainda produz sucessivamente formas elevadas no total", ${ }^{20}$ ou, então: a "cultura, como a vida, passa por evolução geral e específica" (SAHLINS; SERVICE 1988 , p. 23 - grifos nossos). ${ }^{21}$

Para ilustrar o uso prático desses conceitos, Sahlins recorre à História. Nesse sentido, ele formula a seguinte pergunta: "é o feudalismo um estágio geral na evolução de formas econômicas e políticas, um antecedente da moderna economia nacional?"(SAHLINS; SERVICE 1988, p. 30-31 - grifo do autor). ${ }^{22}$ Sua resposta é: não. Dizer que o feudalismo é um estágio geral constitui uma afirmação falaciosa, pois "obscurece o curso histórico do desenvolvimento dessas civilizações, a despeito do quanto ela possa iluminar o curso histórico da cultura Ocidental". ${ }^{23} \mathrm{Na}$ verdade, ao invés de representar um estágio geral, o feudalismo não passa de um estágio específico, isto é, somente "um passo no desenvolvimento de uma linha da civilização". ${ }^{24}$ Isso significa que o feudalismo não representa um avanço qualitativo na história do Ocidente. Portanto, se quisermos entender o surgimento da civilização ocidental, devemos ignorar a época feudal e voltar nossa atenção para duas civilizações antigas: Grécia e Roma (SAHLINS; SERVICE 1988, p. 31-32).

Prosseguindo em seu argumento, Sahlins decide repetir a mesma estratégia adotada por Leslie White: construir uma definição de evolucionismo a partir de sua oposição à História. Seguindo essa lógica, Sahlins escreve que "o atual ressurgimento do evolucionismo na Antropologia é, com a exceção de [Leslie] White, orientado para o específico de forma decisiva", ${ }^{25}$ além de historicamente orientada (SAHLINS; SERVICE 1988, p. 41). Essa inclinação tem sua origem na "esterilidade intelectual do empirismo boasiano e suas tão restritas preocupações históricas" 26 - e aqui vemos a continuidade da longa oposição de Leslie White a Franz Boas (SAHLINS; SERVICE 1988, p. 2). Mas isso não é tudo. Sahlins defende também que essa preocupação
19. No original: "culture continues the evolutionary process by new means".

20. No original: "culture diversifies by adaptive specialization and still it successively produces over-all higher forms".

21. No original: culture, like life, undergoes specific and general evolution".

22. No original: "is feudalism a general stage in the evolution of economic and political forms, the one antecedent to modern national economy?".

23. No original: "obscures the historic course of development of these civilizations, however much it may illuminate the historic course of Western culture".

24. No original: "a step in the development of one line of civilization".

25. No original: "the current revival of evolutionism in anthropology is, with the exception of White, decisively specifically oriented". 
histórica "tem ocasionado uma rica controvérsia em anos recentes sobre as relações entre 'história' e 'evolução'"'27 (SAHLINS; SERVICE 1988, p. 42).

Entre os participantes dessa controvérsia estão Leslie White e Alfred Kroeber. White, segundo Sahlins, defende que a História está voltada para o estudo de "sequências únicas de eventos localizados no tempo e espaço"; ${ }^{28}$ enquanto a evolução se refere à progressão de formas culturais diferentes. A cultura, segundo essa lógica, deve ser abstraída de tempos e espaços específicos. Kroeber, em contrapartida, argumenta que o processo evolutivo já é um tipo de processo histórico, algo que pode ser comprovado quando vemos narrativas construídas por historiadores semelhantes ao que White associa a evolução (SAHLINS; SERVICE 1988, p. 42-43).

Como resposta a essa controvérsia, Sahlins oferece sua própria distinção entre evolução geral e evolução específica. Uma sugestão é que a expressão evolução específica seja usada para denominar o desenvolvimento histórico de formas culturais particulares, como Feudalismo e Antiguidade. Outra sugestão é que a evolução geral seja empregada para designar a sequência progressiva de tipos ou classes que agrupam várias formas culturais, como a Civilização Ocidental ou a Civilização Asiática. Assim, a posição de Kroeber é conciliada com aquela de White: a história de Kroeber equivale à evolução específica; enquanto a evolução de White corresponde à evolução geral (SAHLINS; SERVICE 1988, p. 43-44). Ambas, portanto, se completam.

Essa conciliação foi muito elogiada por Leslie White, para quem Sahlins conseguiu "esclarecer de uma vez por todas a antiga confusão entre história e evolução" (SAHLINS; SERVICE 1988 , p. viii). ${ }^{29}$ O elogio de White, porém, teve um custo: as críticas feitas por Kroeber foram simplesmente ignoradas por Sahlins. Uma das consequências disso é o fato de esse último preservar em seu texto duas das características dos artigos de White: a ausência de historiadores e o mito historiográfico do historiador convencional (por exemplo: SAHLINS; SERVICE
26. No original: "intellectual sterility of Boasian empiricism and its so very restricted historical concerns".

27. No original: "has occasioned a rich controversy in recent years about the relations between 'history' and 'evolution'".

28. No original: "unique sequences of events located in time and space".

29. No original: "clear up once and for all the long-standing confusion between history and evolution". 
1960, p. 42 e 43). Contudo, é importante notarmos que Sahlins faz isso na mesma coletânea em que seu colega Elman Service menciona autores específicos que escreveram livros de História: Oswald Spengler e Arnold Toynbee (SAHLINS; SERVICE 1960, p. 94 e 101).

Com o passar do tempo, entretanto, algumas coisas mudam. Depois da publicação do Evolution and Culture, em 1960, White e Sahlins seguem caminhos diferentes. White manterá sua definição de História construída em 1938 até o fim da vida (por exemplo: WHITE 2005, p. 8-9 e 229-230; WHITE 2007 , p. 30). Sahlins, enquanto isso, torna-se uma estrela em ascensão do movimento evolucionista norte-americano (KUPER 1999, p. 164). Apesar disso, em meados da década de 1960, ele se mostra cansado de Michigan; enquanto isso Leslie White se torna uma figura limitadora para o seu crescimento intelectual (GOLUB; KELLY; ROSENBLATT 2016, p. 12). A abordagem evolucionista, ao mesmo tempo, começa a dar sinais de esgotamento. Como consequência disso, muitos de seus adeptos decidem abandoná-la para trabalhar com estudos biográficos; enquanto outros decidem se aproximar da História e do Marxismo (PATTERSON 2001, p. 143).

Sahlins escolhe se afastar do pensamento de Leslie White e do evolucionismo, buscando sua renovação intelectual na obra do antropólogo francês Claude Lévi-Strauss. As semelhanças entre as obras de White e Lévi-Strauss contribuíram para que esse último fosse escolhido. Por exemplo: ambos se preocupavam com os aspectos simbólicos da existência humana, além de terem enfatizado questões de parentesco e adotado uma visão panorâmica no estudo de sociedades. Lévi-Strauss, além disso, como outros intelectuais franceses, tentou conciliar o estudo do aspecto material da existência humana com a análise de seu aspecto simbólico. White, a seu modo, também buscou essa mesma conciliação (GOLUB; KELLY; ROSENBLATT 2016, p. 13).

Assim, influenciado por Lévi-Strauss, Sahlins abandona a perspectiva evolucionista por volta da década de 1970. Uma evidência desse abandono pode ser encontrada no livro de sua 
autoria, publicado em 1976, chamado Culture and Practical Reason (Cultura e Razão Prática). Seu objetivo, nessa obra, é criticar o que ele mesmo chama de razão prática - uma suposta forma de pensar, a qual interpreta as relações humanas em termos de suas relações materiais, como trocas econômicas, e concebe a cultura como apenas um entre tantos outros produtos dessas relações. Sahlins se opõe a essa razão prática, defendendo uma razão simbólica, a qual enfatiza os símbolos e significados compartilhados por indivíduos na sociedade. De acordo com essa forma de pensar, significados são atribuídos às relações materiais a partir da cultura, não o contrário. E é isso que dá a cada sociedade e cultura suas especificidades - a despeito das semelhanças de suas condições materiais (SAHLINS 1976, p. vii-viii).

Contudo, é somente na década de 1980 que a ausência de historiadores e o mito historiográfico do historiador convencional chegam ao fim nos textos de Sahlins. Isso pode ser visto em pelo menos três de seus textos: Historical Metaphors and Mythical Realities: Structure in the Early History of the Sandwich Islands Kingdom (Metáforas Históricas e Realidades Míticas: Estrutura no Início da História do Reino das Ilhas Sandwich), publicado em 1981; Individual Experience and Cultural Order (Experiência Individual e Ordem Cultural), publicado em 1982; e Islands of History (Ilhas de História), publicado em 1985. Se antes a palavra evolução ocupava um lugar central em suas reflexões, agora é o termo cultura que assume o seu lugar. As suas referências teóricas também mudam: no lugar de Leslie White, aparece Lévi-Strauss. A obra desse último, além disso, vem acompanhada da discussão de outros autores, como os linguistas Roman Jakobson e Ferdinand de Saussure (SAHLINS 1981,1985 e $2005 a$ ).

Em meio a tantas referências novas, uma em particular chama a nossa atenção: Sahlins começa a ler, citar e discutir obras de historiadores. Vemos, por exemplo, diversas menções a historiadores franceses, como Marc Bloch, Fernand Braudel, Jacques Le Goff e Pierre Nora (por exemplo: 
SAHLINS 1985, p. ix, xiv, 20 e 31; ver também as notas de rodapé nas páginas 33 e 125 dessa mesma obra). Sua definição de História, com isso, enriquece e se transforma. Agora, ao invés de escrever sobre evolução geral e evolução específica, Sahlins analisa as "relações históricas que ao mesmo tempo reproduzem as categorias culturais tradicionais e dão a elas novos valores" (SAHLINS 1985, p. 125). ${ }^{30}$ A História passa a ser vista como um produto de categorias que são elas mesmas construídas historicamente (SAHLINS 1985, p. vii). Além disso, novas lições são assimiladas: "Marc Bloch nos ensinou a ser comparativistas, ou então somos antiquários" (SAHLINS 1985, p. 20). ${ }^{31}$ A figura do historiador convencional é substituída por um grupo inteiro ligado à perspectiva teórica conhecida como História Nova. Essa perspectiva aparece em seus textos como estando voltada para o diálogo com as Ciências Sociais, além da análise de estruturas culturais e sociais ao longo de décadas e séculos - como certas formas de agir e pensar comuns a nações e povos inteiros (SAHLINS 1985, p. 72). Sahlins começa, assim, um novo período em seu diálogo com a História.

\section{Consideraçōes finais: História, ausência e mito historiográfico}

Iniciamos este artigo com uma breve análise da relação entre História e Antropologia nos Estados Unidos. Começamos com a obra do antropólogo alemão Franz Boas, alguém que aproximou História e Antropologia, afastou-se do Evolucionismo e veio a se transformar em um oponente teórico dos norteamericanos Leslie White e Marshall Sahlins décadas depois. Em seguida, acompanhamos um duplo afastamento realizado por importantes antropólogos: da História e da obra de Boas. Como evidência disso, citamos dois antropólogos: RadcliffeBrown e George Murdock. Depois, voltamos nossa atenção para alguém que radicalizou esse afastamento: Leslie Alvin White. Argumentamos que essa atitude de White resultou em uma definição de História bastante limitada, formada pela ausência de historiadores e um mito historiográfico do historiador convencional. Mostramos que tanto essa definição quanto esse
30. No original: "historical relationships that at once reproduce the traditional cultural categories and give them new values".

31. No original: "Marc Bloch taught us to be comparativists, or else we are antiquarians". 
afastamento foram criticados por outro antropólogo, o norteamericano Alfred Louis Kroeber. Contudo, essas críticas foram desprezadas por White.

Até aproximadamente a década de 1970, Sahlins repetiu a mesma estratégia de White: aderiu ao Evolucionismo, adotou a ausência de historiadores e recorreu ao mito historiográfico do historiador convencional. O evolucionismo será abandonado na década de 1970 por ele. O fim da ausência de historiadores e da figura do historiador convencional, porém, só ocorrerá na década de 1980. A definição de História de Sahlins, como aquela de White, era alimentada por um círculo vicioso: um mito historiográfico que fazia da menção e da discussão de historiadores específicos algo dispensável; essa ausência, por sua vez, contribuiu para a manutenção e reprodução do mesmo mito. Isso ajuda a entendermos o motivo de Sahlins ter ignorado as críticas de Kroeber durante tanto tempo. E também a razão do interesse de historiadores e antropólogos pelas obras publicadas por ele na década de 1980 - um momento em que sua definição de História se torna mais rica, graças, em parte, ao fim desse círculo vicioso.

Esperamos, assim, contribuir para o estudo de um aspecto específico da biografia intelectual de Sahlins: sua relação com a História. Segundo alguns autores, ela é marcada por uma forma de praticar a Antropologia que permanece consistente ao longo do tempo: "humanista, logicamente rigorosa, ricamente empírica e generalizante", ${ }^{31}$ voltada para a clarificação do "significado e implicações do conceito de cultura" (GOLUB; KELLY; ROSENBLATT 2016, p. 6). ${ }^{32}$ Outros defendem que uma parte de sua obra - seus escritos sobre os povos do Pacífico - pode ser divida em um primeiro momento, comparativo, materialista e evolucionista, e um segundo, estruturalista e historicamente informado (GOLDSMITH 2006). Existem ainda aqueles que defendem uma separação entre o primeiro Sahlins, inspirado no marxismo e guiado pelo desejo de corrigir aspectos da Antropologia norte-americana, e o segundo Sahlins, voltado para a correção do marxismo por meio de Claude Lévi-
32. No original: "humanistic, logically rigorous, richly empirical, and generalizing".

33. No original: "meaning and implications of the culture concept". 
Strauss (KUPER 1999, p. 200). Diante dessas interpretações, neste artigo, nós propomos a existência de um Sahlins ainda pouco explorado: um antropólogo que teve sua definição de História limitada, em parte, por um círculo vicioso formado por historiadores ausentes e um mito historiográfico do historiador convencional; mas que soube mudar essa definição, também em parte, quebrando o mesmo círculo - um evento cujas consequências teóricas são estudadas até hoje.

\section{REFERÊNCIAS BIBLIOGRÁFICAS}

BARNARD, Alan. History and theory in anthropology. Cambridge: Cambridge University Press, 2000.

BIERSACK, Aletta. Local knowledge, local history: Geertz and beyond. In: HUNT, Lynn (ed.). The new cultural history. Berkeley: University of California Press, 1989, p. 72-96.

BURKE, Peter. History and social theory, second edition. 2. ed. Ithaca: Cornell University Press, 2005.

GOLDSMITH, Michael. The evolution of Marshall Sahlins. In: LAL, Brij V.; MUNRO, Doug (orgs.). Texts and contexts: reflections in Pacific Islands historiography. Honolulu: University of Hawai'i Press, 2006, p. 76-86.

GOLUB, Alex; KELLY, John D.; ROSENBLATT, Daniel. Introduction: a practice of anthropology - the work of Marshall Sahlins, so far. In: (orgs.). A practice of anthropology: the thought and influence of Marshall Sahlins. Montreal: McGill-Queen's University Press, 2016.

HARRIS, Marvin. The rise of anthropological theory: a history of theories of culture. Walnut Creek: Altamira Press, 2001. 
HARTOG, François. Regimes de historicidade: presentismo e experiências do tempo. Belo Horizonte: Autêntica Editora, 2013.

KROEBER, A. L. History and evolution. Southwestern Journal of Anthropology, v. 2, n. 1, p. 1-15, 1946.

KUPER, Adam. Culture: the anthropologists' account. Cambridge: Harvard University Press, 1999.

PATTERSON, Thomas C. A social history of anthropology in the United States. Oxford: Berg, 2001.

PEACE, William J. Leslie A. White: evolution and revolution in anthropology. Lincoln: University of Nebraska Press, 2004.

RADCLIFFE-BROWN, A. R. Structure and function in primitive society. New York: The Free Press, 1965.

SAHLINS, Marshall. Culture and practical reason. Chicago: The University of Chicago Press, 1976.

. Historical metaphors and mythical

realities: structure in the early history of the Sandwich Islands kingdom. Ann Arbor: The University of Michigan Press, 1981.

. Individual experience and cultural order. In: . Culture in practice: selected essays. New York: Zone Books, 2005a, p. 277-291.

. Introduction. In: . Culture in practice: selected essays. New York: Zone Books, 2005b., p. 9-32.

Islands of history. Chicago: The University of Chicago Press, 1985.

Social stratification in Polynesia. Seattle: 
University of Washington Press, 1958.

SAHLINS, Marshall; SERVICE, Elman (orgs.). Evolution and culture. Ann Arbor: The University of Michigan Press, 1988.

SERVICE, Elman R. Leslie Alvin White: 1900-1975. American Anthropologist, v. 78, 1976. Disponível em: https://goo.gl/Vn2YJg. Acesso em: 04 jan. 2018.

SCHWARCZ, Lilia Moritz. Apresentação: Marshall Sahlins ou por uma antropologia estrutural e histórica. Cadernos de Campo, Brasil, v. 9, n. 9, p. 125-133, 2000. Disponível em: https://goo.gl/tkYVCN. Acesso em: 04 jan. 2018.

As barbas do imperador: D. Pedro II, um monarca nos trópicos. 2. ed. São Paulo: Companhia das Letras, 2006.

STOCKING, JR., George W. A Franz Boas reader: the shaping of american anthropology, 1883-1911. Chicago: University of Chicago Press, 1974.

. Race, culture, and evolution: essays in the history of anthropology. Chicago: The University of Chicago Press, 1982.

WHITE, Leslie A. History, evolutionism, and functionalism: three types of interpretation of cultures. Southwestern Journal of Anthropology, v. 1, n. 2, p. 221-248, 1945.

. Science is sciencing. Philosophy of Science, v. 5, n. 4, p. 369-389, 1938.

. The evolution of culture: the development of civilization to the fall of Rome. Walnut Creek: Left Coast Press, 2007.

. The science of culture: a study of man and civilization. New York: Percheron Press, 2005. 
AGRADECIMENTOS E INFORMAÇŌES

\section{Felipe Souza Leão de Oliveira}

felipesldoliveira@gmail.com

Doutor em História

Universidade Federal do Rio Grande do Sul

Rua Érico Veríssimo, 3425, Candelária,

Natal, Rio Grande do Norte, CEP 59065-460

Brasil

Agradeço a toda a equipe da História da Historiografia pelas valiosas leituras, críticas e sugestões. 